\title{
Track Marks
}

National Cancer Institute

\section{Source}

National Cancer Institute. Track Marks. NCI Thesaurus. Code C126656.

Visible marks on the skin caused by puncture wounds, most commonly associated with intravenous drug use. 